\title{
Aprendizaje del objeto fracción en un contexto rural.
}

\section{Learning the object fraction in a rural context.}

\author{
Juan Carlos Jaimes Valbuena ${ }^{1}$ \\ Nelsy Rocío González Gutiérrez² \\ Carlos Arturo Carvajal Pulido ${ }^{3}$
}

UPTC

\section{RESUMEN}

Las múltiples aplicaciones del objeto matemático fracción en la vida cotidiana requieren que, en la escuela, su enseñanza suscite especial atención por parte del docente. Por ello, en esta Investigación Acción en el Aula, con enfoque cualitativo, surgió la pregunta: ¿Cómo favorecer el aprendizaje del objeto fracción y sus representaciones semióticas, en estudiantes de grado cuarto y quinto del sector

$1 \quad$ Licenciado en Educación Básica con énfasis en Matemática. Estudiante de Maestría en Educación Matemática. Docente de Básica Primaria de la Institución Educativa Las Mercedes sede Golondrinas Municipio de Chiscas. Email: juancarlos.jaimes@uptc.edu. co Tel: 3214576671 https://orcid.org/0000-0001-6846-4782 https://scholar.google.es/citations?view op $=$ new articles\&hl=es\&imq=Juan+Carlos+Jaimes+Valbuena\#

2 Docente Universidad Pedagógica y Tecnológica de Colombia. Doctora en Ciencias de la Educación, UPTC, Magister en Ciencias Matemáticas Universidad Nacional de Colombia-Bogotá. Email: nelsy.gonzalez@uptc.edu.co Tel: 3106185230

3 Licenciado en Matemáticas y Física Estudiante de Maestría en Educación Matemática. Docente Institución Educativa Sergio Camargo Miraflores Boyacá Email: aarturismo2@gmail.com Tel: 3123168368 https://orcid.org/0000-0001-9178-0492 rural en aulas multigrado? En este sentido, esta propuesta se encaminó a potenciar el aprendizaje del objeto fracción y sus registros semióticos de representación en escolares con estas características. La implementación se hizo con estudiantes de grados cuarto y quinto de la Institución Educativa las Mercedes, sede Golondrinas del municipio de Chiscas - Boyacá. La investigación se llevó a cabo a partir de una secuencia didáctica basada en el planteamiento y resolución de problemas contextualizados, con marco de referencia en la teoría de representaciones semióticas Duval (2017); ésta se diseñó con base en los resultados de la prueba diagnóstica realizada para tal fin. Se concluyó que, así como nuestros antepasados trabajaban el objeto fracción a partir de aquellos problemas que surgían en su entorno, los estudiantes de esta época pueden construir aprendizajes significativos al abordar los objetos matemáticos a partir de problemas contextualizados, favoreciendo el adecuado uso 
de diversas representaciones semióticas para un mismo objeto matemático.

\section{PALABRAS CLAVE:}

fracción, representaciones semióticas, resolución de problemas, educación rural.

\section{Abstract}

The multiple applications of the mathematical object fraction in everyday life require that, at school, its teaching should be given special attention by the teacher. Therefore, in this Classroom Action Research, with a qualitative approach, the question arose: How to favor the learning of the fraction object and its semiotic representations in fourth and fifth grade students of the rural sector in multigrade classrooms? In this sense, this proposal was aimed at promoting the learning of the fraction object and its semiotic registers of representation in students with these characteristics. The implementation was done with fourth and fifth grade students of the Institución Educativa las Mercedes, Golondrinas branch of the municipality of Chiscas - Boyacá. The research was carried out from a didactic sequence based on the approach and resolution of contextualized problems, with frame of reference in the theory of semiotic representations Duval (2017); this was designed based on the results of the diagnostic test conducted for this purpose. It was concluded that, just as our ancestors worked the fraction object from those problems that arose in their environment, students of this era can build significant learning by approaching mathematical objects from contextualized problems, favoring the appropriate use of diverse semiotic representations for the same mathematical object.

\section{KEY WORDS:}

fraction, semiotic representations, problem solving, rural education.

\section{DESARROLLO}

El ser humano siempre ha tenido necesidades, una de ellas fue la de contar elementos del entorno y reconocer cantidades. Por ello, surgen los números; primero los naturales y más adelante los números de "medir", los racionales e irracionales, que muy seguramente nuestros antepasados los utilizaban cuando debían referirse a cantidades no exactas o "incompletas", requeridas para poder solucionar problemas de repartos y otros del contexto en el cual se desarrollaban aquellas culturas milenarias como la egipcia, hindú y babilónica. Así, con el pasar del tiempo fueron desarrollándose los diferentes sistemas de numeración y entre ellos los racionales.

En algunas aulas de clase las fracciones no son conceptualizadas desde la noción de número racional, generando obstáculos en los estudiantes al momento de comprender el concepto formal de número racional. Comprender que los números racionales constituyen el conjunto de todos los números que se pueden escribir como cociente de dos números enteros , con , facilitará en los estudiantes poder llevar a cabo procesos de conversión entre las diversas representaciones habituales de una fracción. Por ejemplo, atributos propios del ser humano como el peso y la estatura son determinados haciendo uso de números decimales finitos, y por ende de fracciones; lo mismo ocurre con la temperatura corporal, a cuya medida acudimos cuando deseamos saber si tenemos fiebre. Ejemplos como los aquí expuestos abundan en nuestra cotidianidad y afloran con mayor intensidad en contextos rurales. Por esta razón, el problema del presente artículo se centra en la dificultad que tienen los estudiantes para solucionar problemas relacionados con el objeto fracción, y en sí, en la concepción que se tiene de dicho objeto. Como se mencionó antes, no se puede perder de vista que las fracciones son aplicadas en diferentes contextos (medición, 
relación parte todo, razón, proporción y cociente, entre otras); por consiguiente, en la escuela, su enseñanza requiere de especial cuidado por parte del docente, más aún cuando se trabaja con educación básica primaria pues es en esta etapa educativa donde se deben cimentar bases sólidas capaces de soportar estructuras mentales cognitivas que generen aprendizajes significativos. Así mismo, una labor fundamental del docente se centra en evitar obstáculos que impidan el desarrollo de habilidades y competencias de sus estudiantes. En este sentido, Duval (2004), sostiene que "El aprendizaje de las matemáticas constituye, evidentemente, un campo de estudio privilegiado para el análisis de actividades cognitivas fundamentales como la conceptualización, el razonamiento, la resolución de problemas, e incluso, la comprensión de textos" (p. 13). También, este autor afirma que "La particularidad del aprendizaje de las matemáticas hace que estas actividades cognitivas requieran de la utilización de sistemas de expresión y de representación distintos a los del lenguaje natural o de las imágenes" (p. 13). Por consiguiente, en esta Investigación-Acción, con enfoque cualitativo, se buscó potenciar el aprendizaje del objeto fracción y sus registros semióticos de representación, en estudiantes de grados cuarto y quinto de la sede Golondrinas de la Institución Educativa las Mercedes del municipio de Chiscas, a partir de una secuencia didáctica basada en el planteamiento y resolución de problemas contextualizados. Se piensa que, así como nuestros antepasados trabajaban el objeto fracción a partir de aquellos problemas que surgían en su entorno, así, los estudiantes de nuestra época pueden construir aprendizajes muy significativos concretizando los objetos a partir de problemas del entorno de cada estudiante.

Muchos trabajos de investigación muestran que el aprendizaje del objeto fracción es difícil, pues los estudiantes con frecuencia presentan problemas de interpretación y abstracción, más aún cuando se trata de resolver problemas (Martínez y Lascano 2001). El Ministerio de Educación Nacional MEN;, (2007) en los Lineamientos Curriculares para el área de matemáticas, hace énfasis en que el objeto fracción se debe enseñar a partir de la resolución de problemas, ya que, al hacerse de esta manera, los estudiantes desarrollan habilidades como la modelación, el razonamiento y la ejercitación de procedimientos. Este artículo investigativo resalta sustentos teóricos basados en el análisis e historia del objeto fracción a través del tiempo; destacando la manera cómo se resolvieron problemas con fracciones desde sus primeras concepciones. Así mismo, involucra aportes de Polya (1989), en cuanto a cómo plantear y resolver problemas; pero principalmente, se sustenta en los aportes de estudios realizados por Raymond Duval desde la teoría de representaciones semióticas. Duval (2004) En nuestro contexto es muy frecuente escuchar a los estudiantes referirse a las fracciones en lenguaje natural, pero se evidencian grandes dificultades cuando éstas se estudian en forma diferente o mediante otro sistema de representación. El uso de diferentes sistemas de representación de un objeto matemático es vital para lograr su comprensión Duval (2017). Por esta razón la presente investigación también incorpora la implementación de estrategias de aprendizaje haciendo uso de secuencias didácticas.

\section{HISTORIA DEL OBJETO FRACCIÓN A TRAVÉS DEL TIEMPO}

La noción de fracción y sus diferentes concepciones han ido evolucionando a través de la historia de la humanidad. Es evidente descubrir que para el desarrollo de las actuales interpretaciones del objeto fracción se ha hecho necesario esperar muchos siglos y este proceso ha demandado suficiente trabajo por parte del ser humano, dependiendo de sus intereses y necesidades. Es por ello que, para lograr 
un mejor entendimiento se hace realmente importante conocer más a fondo la historia del concepto de fracción, así como su desarrollo a través del tiempo desde las antiguas civilizaciones hasta nuestros días.

\section{¿CÓMO CONTAR Y MEDIR?}

Muy seguramente esta fue una de las preguntas que llevó a los seres humanos a encontrar una de las primeras concepciones de número; las necesidades de contar y medir son menesteres connaturales desde la misma existencia de la humanidad. La necesidad de contar personas, objetos, cosas, animales o bienes de su entorno, pudo hacer que el hombre utilizara los dedos de sus manos y sus pies para hacer pequeñas cuentas y darle uno de los primeros significados al número: "Llamamos número a una entidad abstracta y numeral a su representación en algún sistema" (Gaviria, 2016, p. 20). Pero, la labor de contar con los dedos de pies y manos se hacía precaria o insuficiente a medida que la cantidad era mayor; por ejemplo: cuando los rebaños crecían o las comunidades aumentaban en gran número. Entonces el hombre ideó un primitivo método de "guardar" información acerca de los elementos que contaba. Por ejemplo, usaron huesos o pedazos de madera en los que tallaban diversas marcas que les representaba determinada cantidad (Gaviria, 2016, p. 21), "la referencia más antigua que se tiene de un sistema que permitiera guardar información sobre (cuántos hay) se encuentra en el hueso de Ishango, descubierto por el belga Jean de Heinzelin de Braucourt, en 1960, mientras hacia una exploración en Ishango, África" (Gaviria, 2016, p. 21).

Así mismo, se debe ser precavido cuando hablamos de fracción; "El vocablo 'fracción' tiene su origen etimológico en la locución latina fractio, que traduce división, fractura o rotura" (Gaviria, 2016, p. 21). En el mismo estudio el autor afirma que "Juan de Luna (1575 - 1645) fue el primero en usar esta definición, cuando al compilar algunos escritos históricos de Al'Khwarizmi tradujo del árabe el término al-Kasr que significa quebrar o romper". Pero, según Flores y Morcote, (2001), citado también por Gaviria (2016), se tiene que: "Así como el hombre empezó a contar a partir de los números naturales, empezó a medir con los números racionales cuya idea fundamental, históricamente hablando, son las fracciones" ( $p$. 21).

Pudo suceder que en la edad de piedra los hombres no necesitaran las fracciones, por ello no las representaron y no se encuentran datos de ellas; pero, al pasar el tiempo y a medida que evolucionaban y encontraban más necesidades; surgieron las fracciones y las culturas egipcias y babilónicas, estos últimos herederos de "los Sumerios", al dominar gran parte del conocimiento humano dejaron datos de su surgimiento. Uno de los textos matemáticos más antiguos es el Papiro de Rhind hecho por Ahmés hacia el año 1650 a.C. quien fue un escriba apoyado de escritos antiguos de la Dinastía XII de Egipto; este documento es considerado como manual práctico de las matemáticas egipcias; presenta problemas de la vida cotidiana y en ellos están presentes: fracciones, ecuaciones, progresiones, cálculo de áreas y volúmenes de algunas figuras geométricas, aunque con algunos errores en cuanto al planteamiento y soluciones.

Para los egipcios las fracciones eran únicas por eso no las repetían para conformar otra fracción; usaban diversas fracciones y las entendían de la siguiente manera: para conformar $2 / 5$, traducido a nuestro sistema de numeración actual, sería $2 / 5=1 / 5+1 / 10+1 / 15+1 / 30$, esto dio lugar a que grandes matemáticos como Fibonacci (s. XIII) se interesaran por estudiar muy exhaustivamente este problema sobre descomposición de un racional en la suma de fracciones unitarias. Luego, hacia 1880, el matemático inglés J.J. Sylvester (1814 - 1897) también lo investigó a profundidad. 
Para la escritura de fracciones, los egipcios colocaban un símbolo de forma ovalada, que pronunciaban como "ro", sobre otro número y tenían escritura especial para algunas fracciones: "el ojo de Horus" Figura 1 y Figura 2

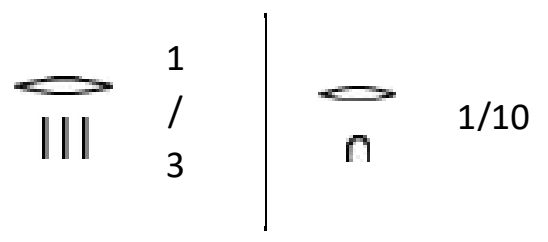

Fig. 1 Uso del símbolo "ro". Fuente:

https://es.wikipedia.org/w/extensions/wikihiero/img/hiero D21.png?9bfb9
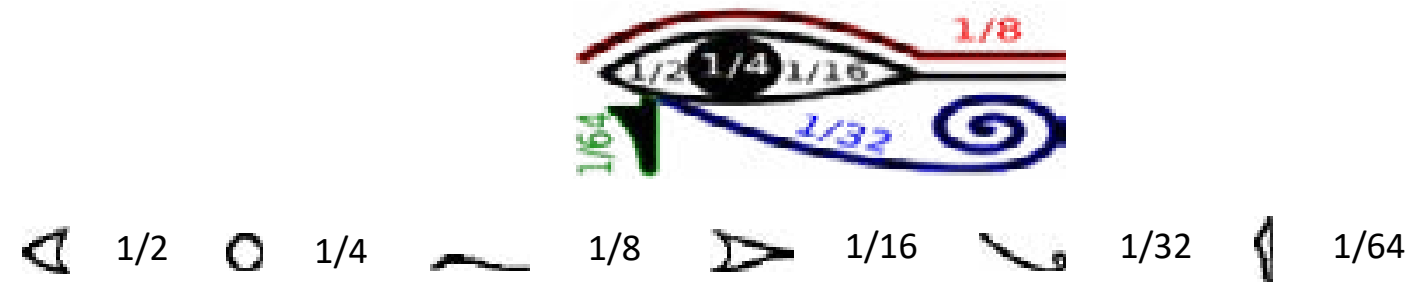

Fig. 2 El ojo de Horus; fracciones con escritura especial. Fuente:

https://upload.wikimedia.org/wikipedia/commons/thumb/2/25/Oudjat.svg/220px-Oudjat.svg.png

En cuanto a la cultura babilónica, se hace conocimiento que ellos empleaban un sistema de numeración posicional de base 60 y fueron los primeros en dar una representación para el cero; lo indicaban con una posición vacía con dos cuñas inclinadas, pero se presentaban confusiones ya que lo usaban solo en cifras intermedias. Se cree que usaron el sistema sexagesimal debido a la cantidad de divisores que posee el $60,(60,30,20,15,12,10,6,5,4,3,2,1)$, y gracias a ello lograron calcular aproximaciones extraordinariamente cercanas a las ofrecidas por nuestras actuales calculadoras. Un ejemplo de ello se encuentra en la tablilla de barro babilónica "YBC 7289" Figura 3 que muestra el trazo de la diagonal de un cuadrado y su valor realmente cercano al que hoy conocemos como $\sqrt{2}$ :



Fig. 3 Tablilla de barro babilónica YBC 7289 . Fuente: https://encrypted-tbn0.gstatic.com/ images?q=tbn\%3AANd9GcSERP17Oz zKL-ckjjafA98gyNOg_duCohXB3n_LUuo$\underline{x c C t j 5 r \& u s q p=C A U}$

La secuencia 1245110 que muestra la figura, sobre la diagonal marcada, representa la siguiente suma de fracciones sexagesimales: $1+24 / 60^{1}+51 / 60^{2}+10 / 60^{3}$ cuyo resultado es 1,414212963 y que, comparada con el valor de hoy en día, $\sqrt{2}:=1,414213562$, sorprendentemente arroja un insignificante error valorado en 0,000000599 . 
Los chinos conocían muy bien las operaciones con fracciones ordinarias, hasta el punto de hallar el mínimo común denominador de varias fracciones. Como era su costumbre asignaban un rol femenino y otro masculino a los elementos que componen la división Figura 4. La adopción de un sistema decimal en pesos y medidas dio como resultado que se impusiera el ámbito decimal en el manejo de las fracciones.

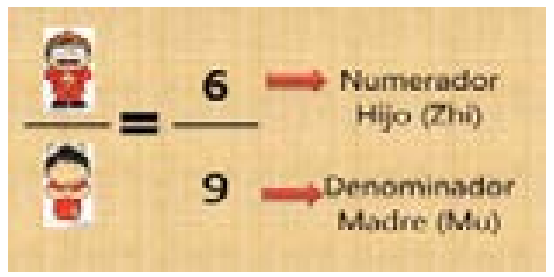

Fig. 4 Método Chino para simplificar

fracciones. Fuente https://www.youtube.com/ watch? $=\mathrm{f} 4 \mathrm{~g} 3 \mathrm{vh} 3 \mathrm{k} 2 \mathrm{Mg}$

Unos 100 años después de Cristo los chinos ya utilizaban fracciones decimales y de ahí se extendió su uso a Medio Oriente y Europa. Los hindúes establecieron reglas para evitar operaciones con fracciones; este trabajo lo inició Aryabhata y después fue continuado por Bramagupta en el siglo XII.

"El nombre de fracción como tal, se debe a Juan de Luna, quien lo tradujo del latín, en el siglo $\mathrm{XI}$, en el libro de aritmética de "Al-Juarizmi". Él empleó la palabra "FRACTIO" para traducir la palabra árabe "al-Kasar", que significa QUEBRAR, ROMPER” (Gaviria, 2016, p. 21).

En lo que respecta al uso del vínculo para representar fracciones se tiene que "Leonardo de Pisa, más conocido por su apodo Fibonacci, introdujo en Europa la barra horizontal para separar numerador y denominador en las fracciones" (Plata, 2020 p. 11).

Para el siglo XVI, según Plata (2020), Simon Stevin, considerado como el precursor del uso moderno de los fraccionarios, publicó De Thiende, un tratado científico de treinta y seis páginas en el que se introduce el uso sistemático de las fracciones decimales. Stevin indicó que, a la derecha de las unidades, podrían incluir una coma y tras ella, las unidades, decenas y así sucesivamente para presentar las fracciones. A partir del año 1700 , fue cuando se hizo un uso generalizado de las fracciones hasta como se conoce hoy en día.

\section{LOS PROBLEMAS CON FRACCIONES EN LA ESCUELA.}

Desde los comienzos de la humanidad lo que ha hecho emerger el conocimiento es la necesidad que ha tenido el hombre para resolver problemas. Los antecedentes de los problemas con fracciones, se remontan a las antiguas culturas matemáticas, mesopotámicas, egipcia, china e hindú, anteriores a la era cristiana. De los problemas, se puede decir que han venido evolucionando a lo largo del tiempo adaptándose a los cambios sociales, acontecimientos históricos, desarrollos matemáticos, teorías pedagógicas, y en sí, a las necesidades del ser humano. El hombre siempre tendrá necesidades y para su solución deberá mejorar o adaptar sus saberes. Si bien es cierto que, los enunciados han evolucionado también según Gómez et al. (2016) su contenido matemático se ha conservado y estandarizado bajo la forma de problema tipo (o estereotipo). Y por esta razón, aún encontramos estas clases de problemas en libros de texto actuales, aunque con algunas modificaciones de tipo contextual.

Según Gómez et al. (2016) en la actualidad, los problemas descriptivos emergen con renovado interés en las propuestas curriculares pues consideran que la resolución de problemas es una competencia básica en el desarrollo del pensamiento aritmético y algebraico; los aspectos históricos son esenciales en las actuales tendencias de resolución de problemas y se hace necesario su entendimiento y sus métodos matemáticos. En este sentido, se mencionan en este trabajo algunos problemas descriptivos de 
fracciones, con el fin de clasificarlos teniendo en cuenta al autor mencionado. A continuación, encontramos algunos de ellos:

Ejemplos de estos problemas según Gómez et al. (2016) son:

Un hombre compra 4 piezas de tela por 80 bezantes. Compra la primera por un precio, y otra por $2 / 3$ del precio de la primera. Compra la tercera por $3 / 4$ del precio de la segunda. Además, la cuarta, la compra por $4 / 5$ del precio de la tercera. ¿Cuánto vale cada pieza? (Fibonacci, 1202/2002, p. 274-275)"

"Un moribundo dejó 6000 escudos para distribuir de esta forma; "Quiero", dijo, "que la mitad se dé al monasterio de los Jacobitas; la tercera parte, al convento de San Agustín; la cuarta parte, al cenobio de los hermanos menores; y la quinta parte, a la orden de los carmelitas". Pregunta: si el total es de 6000 escudos, ¿cuánto corresponde a cada orden? (Siliceo, 1513/1996, p. 266).

La lanza. Aquí hay una lanza, que la $1 / 2$ está en el fango y $1 / 3$ está en el agua y fuera del agua tiene 7 palmos y $1 / 4$. Pide cuanto es de largo la lanza (Santcliment, 1482/1998, p.p. 311-312).

Me encontré con una piedra, pero no la pesé; después de quitarle $V 7$ y luego $V 13$ [de lo que quedaba], encontré que pesaba 1 manna. ¿Cuál era el peso original de la piedra? (Mesopotamia, Katz 2003, p. 27).

A los anteriores problemas el mencionado autor los clasifica de la siguiente manera: al del moribundo un problema con partes no relacionadas donde todo es conocido; al de la tela un problema con partes relacionadas donde todo es conocido; al de la lanza un problema con partes no relacionadas donde todo es desconocido y al de la piedra un problema con partes relacionadas donde todo es desconocido. Para revisar cada una de las soluciones el lector puede recurrir a (Gómez et al. 2016, p.p. 6-16).

Otra autora que hace un estudio valioso relacionado con los problemas matemáticos en la historia es Fandiño (2010), la cual mencionaremos en los próximos párrafos. Ella afirma que "hacer matemáticas" coincide con "resolver problemas" y que la historia de la matemática coincide, con problemas que fueron puestos en el curso de los siglos y que podemos hoy considerar "clásicos". En este apartado nos referiremos a uno en especial, el cual está relacionado con fracciones; que se atribuye a los árabes y que según Fandiño (2010) Giuseppe Peano lo propone así:

Un árabe muriendo dejo a sus tres hijos 17 camellos como herencia y ordenó que la mitad de estos fuera dada al primer hijo, la tercera parte al segundo, y la novena parte al tercer hijo. Los tres hijos se dirigieron al cadi, quien llegó con su propio camello. Dio la mitad de los 18 camellos, es decir 9, al primero; un tercio, es decir 6 , al segundo; un noveno, es decir 2, al tercer hijo. Después tomó su camello y se fue con el agradecimiento de los tres hijos, cada uno de los cuales había recibido más de lo que le correspondía.

Este singular acertijo ha tenido muchas variantes, retomado en varias partes del mundo por Maestros del Ábaco, como Paolo del Ábaco (1281 -1374), por Dionigi Gori en el siglo XVI y recientemente por Gardner (1979) y por Tahan (1997). Es importante aclarar que esta clase de acertijos en muchos casos ha sido utilizada como diversión, pero contemporáneamente ha tomado gran valor en la didáctica de la matemática. 


\section{LOS REGISTROS SEMIÓTICOS DE REPRESENTACIÓN.}

Para muchos autores de hace varios siglos, y para autores contemporáneos; el desarrollo de la matemática está muy relacionado con los sistemas de representación semiótica. Muchos afirman que es suficiente recordar la diversidad y la evolución de todos los sistemas de representación de los números; los objetos matemáticos no son accesibles perceptivamente o instrumentalmente como otros dominios de conocimiento científico. Los objetos matemáticos son perceptibles a través de los sistemas semióticos de representación y eso sucede gracias a las necesidades de enseñanza y aprendizaje con estudiantes desde preescolar hasta la universidad y más en adelante. Por este motivo se presenta a continuación un apartado que reivindica el valor de la semiótica, su historia y evolución.

Según D`Amore et al. (2013), "la semiótica y la matemática nacieron y crecieron juntas, una al lado de la otra, ayudándose y sosteniéndose entre sí, a espaldas de todos, por mucho tiempo" (p. 21). En este momento, casi todos los estudiosos de la didáctica de la matemática han evidenciado el papel de la semiótica en la enseñanza y el aprendizaje de la matemática. Raymond Duval (1993), Radford (1997), D`Amore (2007) y Godino (2002), son autores e investigadores que resultan de gran utilidad para el enfoque teórico de este trabajo. A continuación, se evidencian los orígenes del término "semiótica".

Para Deely (2003), "El término "semiótica" tiene orígenes antiquísimos. Ya en la antigua Grecia existía el término (semeion), traducido usualmente como "signo", que constituye la raíz etimológica, aunque no conceptual, de la palabra "semiótica" denotaba para ellos una interacción de naturaleza física, no social, o una relación de inferencia.
Según D`Amore et al. (2013)

El término "semiótica" (semiotics) aparece por primera vez en An American Dictionary of the English Language de Noah Porter (1870), con la misma definición del término "semiología" (semilogy), que aparece veinte años antes, en el diccionario de Chauncey A. Goodrich (1850). En este último, el término "semiologia" (semiology) se define como "aquella parte de la medicina que trata los signos de las enfermedades", aparece junto al término "semiótico" (semiotic, sin la "s" final): "relativo a los signos o a los síntomas de las enfermedades". (p. 23)

Finalmente, Deely (2003) "En el diccionario editado por Charles Annandale, (1883) los términos "semiología" (semiology) y "semiótica" (semiotics) se definen ambos en términos ya no exclusivamente "naturalísticos" o médicos, sino, en primer lugar, en términos de "doctrina" o "ciencia" de los signos." (p.p 1-49)

Según D`Amore et al. (2013) para Platón (428 374) "no hay una teoría de signo completamente separada de la teoría del lenguaje. A lo que nosotros llamamos "signo lingüístico" él lo llama "nombre" y los nombres sean estos naturales o convencionales, son representaciones parciales, incompletas de la verdadera naturaleza de las cosas y es necesario tener un conocimiento más amplio de las "cosas" es decir, acceder a más representaciones" (p. 23).

Otro aporte importante y muy conocido lo hace Kant, pues según Radford (2004) "Kant sostiene que entre la cosa en sí y el fenómeno existe una fractura. Existe una fractura que no podemos colmar. Este es el problema de lo incognoscible de las cosas en sí (p. 39). En otras palabras, Kant afirma que aquello de lo cual no tenemos conocimiento no es la realidad misma: lo que nosotros conocemos es únicamente aquello que 
nos llega a través de las sensaciones". Entonces según D`Amore et al. (2013) el conocimiento para Kant no es una simple representación de la realidad externa, sino que es una transformación o reconstrucción de la realidad, de los objetos de la experiencia sensible, por parte del sujeto que aprende, sobre la base de las estructuras cognitivas poseídas por él. Kant con esta afirmación da un inicio importante a lo referente con las transformaciones de los objetos matemáticos por parte de la persona que aprende; él cree que si el estudiante no tiene o no puede transformar un objeto es incapaz de acceder a él.

Por otro lado, Sanders (1976), quien es considerado el fundador de la semiótica moderna, un genio universal en muchas ciencias, reconocido como el más grande filósofo estadounidense. Peirce, con la teoría de los signos, se funda en la idea de que la cognición, el pensamiento e incluso el ser humano tienen una naturaleza esencialmente semiótica. Según Peirce, los signos son medios para representar cosas para alguien, son medios de pensamiento, de comprensión, de razonamiento, de aprendizaje. Entonces, una de las definiciones que da Peirce según D`Amore, et al. (2013) es:

Un signo o representamen, es algo que para alguien está por algo bajo algún aspecto o capacidad. Se dirige a alguien, esto es, crea en la mente de esa persona un signo equivalente, o tal vez un signo más desarrollado. Este signo que crea lo llamo interpretante del primer signo. El signo está por algo, su objeto. Está por ese objeto no bajo todos los aspectos, sino con referencia a una cierta idea, que a veces he llamado ground del representament. (p. 55)

Lo anteriormente expuesto lo explica D`Amore et al. (2013) de la siguiente manera:
De esta definición emerge una relación fundamental que involucra tres elementos: un representamen, es decir el vehículo, la parte "material" del signo; un objeto, eso a lo cual el representamen reenvía; un interpretante, es decir lo que deriva o viene generando de la relación entre representamen y el objeto. (p. 55)

Podría entonces afirmarse que lo mencionado aquí constituye las bases de los estudios que se adelantan actualmente con la "semiótica" ya que entre otras cosas se estudia el "objeto" a partir de las representaciones teniendo en cuenta los saberes previos y experiencias precedentes de los estudiantes. Cabe notar el aporte de Piaget, que citado por Radford (2005a, 141) y ahora retomado en D’Amore et al. (2013) evidencia que:

la inteligencia sensorio-motora se prolonga en la representación conceptual. La función semiótica inicia precisamente cuando existe una diferencia entre significantes y significados. Esta diferencia proporciona al significado una permanencia espaciotemporal y abre la posibilidad de que un mismo significante pueda ser relacionado con diversos significados (p. 78).

De esta manera, para Piaget "la función semiótica incluye imitaciones, juego simbólico, imágenes mentales, gestos y lengua natural" (D`Amore et al., 2013 p. 78). En otras palabras, la semiótica juega un papel muy importante en cuanto al entendimiento de los objetos; para su construcción se están utilizando diferentes representaciones tanto mentales como gráficas.

Uno de los autores contemporáneos más importantes en el estudio de la semiótica para el aprendizaje de la matemática es Duval (1996) quien define un registro semiótico, y un sistema semiótico de la siguiente manera: 
Un registro semiótico es como un sistema específico de producción de representaciones semióticas, más precisamente, comounsistemasemiótico que responde no solo a una función de comunicación o de objetivación sino también a una función de tratamiento, es decir de transformación de un objeto en otra (del mismo objeto) al interior del mismo sistema semiótico. Se habla de conversión cuando se pasa de una representación de un objeto en un registro semiótico determinado a una representación del mismo objeto en otro registro semiótico; se trata entonces de una transformación de representación que determina un cambio de registro sin modificar el objeto denotado. Mientras que los tratamientos están estrechamente relacionados con las características del registro semiótico utilizado para la representación de un objeto, no existen reglas específicas de conversión de un registro a otro. Un sistema semiótico es definido por Duval (2006a) como un conjunto de: a) reglas organizativas para combinar o agrupar elementos (signos) en unidades significativas (expresiones, unidades figurales elementales); b) elementos que asumen valor de sentido sólo en oposición de elección a otros elementos y a sus usos según las reglas organizativas que permiten designar objetos (por ejemplo, las cifras de una base de un sistema de numeración). Toda representación semiótica proporciona un contenido (sentido o modo de presentación) diferente según el registro semiótico utilizado para su producción; mientras que el objeto representado se vuelve el invariante de un conjunto de representaciones. Duval (2008) evidencia la estructura, esencialmente didáctica, de una representación semiótica de la siguiente forma: $\{\{$ contenido de la representación, registro semiótico utilizado\}, objeto representado\} (p.p. 349-382).

El desarrollo de esta investigación se centrará en los aportes de Raymond Duval y utilizará sus propuestas metodológicas en cuanto a los registros semióticos de representación para el aprendizaje del objeto fracción; en adelante se evidencian algunos aportes.

Según Duval et al. (2016)

el aprendizaje de las matemáticas tiene una gran importancia si la meta de su enseñanza, en los niveles de primaria y secundaria, no es formar a futuros matemáticos ni tampoco dar herramientas a los estudiantes, que solo posiblemente les serán útiles muchos años más tarde, sino más bien contribuir al desarrollo general de sus capacidades de razonamiento, análisis y visualización".

Esta perspectiva concuerda con los objetivos de esta investigación pues se pretende no hacer que los estudiantes mecanicen métodos o sean matemáticos distinguidos, sino que pretende, formar en el estudiante pensamientos críticos, los cuales, mediante la resolución de problemas contextualizados procuren mejorar su entorno, su forma de pensar y, su forma de vivir. (p. 62)

También Duval afirma que existen dos formas bien diferentes de transformaciones que nunca se tienen en cuenta explícitamente en la enseñanza; desde la perspectiva en matemáticas existe una en especial que requiere mayor atención; la otra causa grandes dificultades a los estudiantes. Hablando acerca de las representaciones semióticas Duval et al. (2016) afirma que:

"la situación epistemológica particular de las matemáticas con respecto a los 
otros campos de conocimiento conduce a conferir a las representaciones semióticas un rol primordial. En primer lugar, constituyen el único medio de acceso a los objetos matemáticos; lo cual plantea el problema cognitivo del paso de la representación de un objeto a otra representación de ese mismo objeto. Luego, y, ante todo, las estrategias matemáticas implican de manera intrínseca la transformación de representaciones semióticas".

Por ende, se puede deducir que las transformaciones semióticas siempre han estado presentes en los procesos de enseñanzaaprendizaje de los objetos matemáticos y del pensamiento matemático en sí.

En cuanto al abordaje de la literatura encontramos a nivel internacional, Cid et al. (2002) quienes dirigieron un proyecto a profesores de matemáticas que tuvo como eje central la didáctica de los sistemas de numeración; ellos analizaron y describieron los enunciados comunes que tienen los libros de matemáticas, específicamente en el tema de fracciones en el cual asumen que éste es un proceso de abstracción a la introducción de los números racionales; para ello, analizaron situaciones prácticas en el aula de clase, enfatizando que el enfoque de la enseñanza de las fracciones debe ser logrado a partir del sentido numérico y la resolución de problemas.

En 2016, en Valencia España, Bernardo Gómez Alfonso, María Teresa Sanz García e Irene Huerta Gabarda, realizaron un trabajo en el cual estudiaron en conjunto los problemas descriptivos de fracciones, allí no sólo pretendieron transmitir conocimiento, sino especialmente prestar atención a aquellos aspectos de la resolución de problemas que tienen que ver con la producción de conocimientos significativos para el que aprende. En él queda presentada una recopilación de problemas de fracciones extraídos de libros de diferentes periodos históricos y agrupados en categorías, atendiendo a las relaciones entre las partes; aportando un conocimiento matemático que puede ser útil para la enseñanza ya que brinda claridad metodológica, en la forma de analizar y organizar los distintos métodos de resolución. En cuanto a la investigación ofrece una metodología para el análisis histórico y epistemológico de un contenido matemático que ha sido transmitido por tradición histórica.

En México, Perera et al. (2009) muestran los resultados del desarrollo de una enseñanza experimental en un grupo de $4^{\circ}$ de primaria. Ellas desarrollaron un programa de enseñanza integrado con actividades en escenarios afines a la vida real de los niños propiciando la construcción de la noción de fracción y el reconocimiento de algunos de sus significados (relación parte-todo, media, cociente intuitivo y rudimentos de operador multiplicativo) por medio de dos cuestionarios uno antes y otro después de la implementación, profundizando con el estudio de tres casos en los procesos de aprendizaje de cada uno de ellos. Lograron mostrar, que al igual que lo planteado por Freudenthal (1983), Streefland $(1991,1993)$ y Goffre (2000) se favoreció la consolidación de la noción de fracción y de algunos de sus significados (relación parte-todo, media, cociente intuitivo y rudimentos de operador multiplicativo) a través de la resolución de situaciones problemáticas de la vida real.

A nivel Nacional Rodriguez (2019), hizo una investigación la cual tuvo como propósito analizar una estrategia didáctica empleada en la enseñanza y aprendizaje de las matemáticas, específicamente en el objeto fracción; en este, los estudiantes lograron apropiarse de algunos significados de fracción, potenciaron saberes específicos, se involucraron en procesos de planteamiento y resolución de problemas 
propios de su contexto para lograr una mirada diferente de las matemáticas.

En el contexto regional y local, Reyes (2018) en su investigación analiza el aprendizaje del objeto fracción a partir de la exploración de sistemas semióticos de representación y sus diversos registros, como parte-todo, porcentaje, decimal y razón. El autor implementó una secuencia didáctica para mejorar el aprendizaje en estudiantes de grado sexto de un colegio privado de Tunja mediante un enfoque cualitativo. Concluye que la apropiación del objeto fracción se logró reconociendo las relaciones y transformaciones de los registros semióticos entre representaciones.

En 2019, Rodríguez presentó una investigación cuyo objetivo fue analizar una estrategia didáctica empleada en la enseñanza y el aprendizaje del objeto fracción. La implementó en un contexto rural en grado sexto. Utilizó un enfoque cualitativo de tipo descriptivo basado en la teoría de representaciones de Duval. El autor concluye que la implementación de procesos de planteamiento y resolución de problemas del contexto permitió la apropiación de algunos significados de fracción e involucró tanto a docentes de la institución como a padres de familia en la implementación de la estrategia didáctica.

El presente artículo se centra en mostrar los primeros resultados arrojados durante el proceso de la investigación. Además, se exhibe la metodología a seguir, el desarrollo de algunas actividades y las conclusiones que se fueron dando a medida que se avanzó en el trabajo de campo.

\section{METODOLOGÍA}

La investigación estuvo orientada desde una visión cualitativa, ya que este paradigma investigativo "se enfoca en comprender los fenómenos, explorándolos desde la perspectiva de los participantes en un ambiente natural y en relación con su contexto" (Hernández et al., 2014 p. 358). Esta óptica encuadra con el propósito de este proyecto, el cual se centró en potenciar el aprendizaje del objeto fracción y sus registros semióticos de representación, en estudiantes de grados cuarto y quinto de la sede Golondrinas de la Institución Educativa las Mercedes, del municipio de Chiscas, a partir del planteamiento y resolución de problemas contextualizados. La selección de la muestra se hizo atendiendo a que estos estudiantes asistían a aula multigrado en la Institución; la cual se encuentra ubicada en una zona rural de difícil acceso, la población se dedica al trabajo agropecuario y el $100 \%$ de las familias se encuentra en un nivel socioeconómico bajo. El investigador principal era el profesor a cargo de estos grados y, los resultados de las pruebas externas presentadas por los participantes evidenciaron rendimientos demasiado bajos en lo inherente a los procesos que involucran el objeto matemático fracción.

Para el desarrollo de esta investigación, primero se determinaron los conceptos que tenían los estudiantes de grados cuarto y quinto sobre el objeto fracción y sus registros semióticos de representación. Luego, a manera de diagnóstico se identificaron los saberes previos de los estudiantes, y a partir de ello, se diseñó y aplicó una secuencia didáctica basada en el planteamiento y resolución de problemas focalizados en los registros semióticos de representación (se pretendió favorecer el aprendizaje del objeto fracción y sus representaciones semióticas). Así, se obtuvo una base metodológica de trabajo e interacción en donde se pudieron valorar las relaciones y transformaciones de los sistemas semióticos de 
representación, del objeto matemático fracción, que poseían los participantes.

Para lo anterior, se tuvo en cuenta la teoría de Duval (2006), quien se ha encargado de hacer importantes estudios en cuanto a objetos de aprendizaje y didáctica. Para la recolección de los datos se realizó un seguimiento a cada uno de los estudiantes mediante observaciones directas, entrevistas semiestructuradas, grabación de material fílmico que evidenció y permitió realizar análisis a la aplicación de la secuencia didáctica para detectar meticulosamente las potencialidades u obstáculos presentes durante el desarrollo de la investigación.

Este estudio se fundamentó en la Investigación Acción considerándola como un modelo actual para la educación pues involucra las prácticas de agentes educativos y permite al docente ser protagonista en función de analizar y mejorar su práctica pedagógica en el aula (Elliott, 2000). Se debe tener en cuenta que:

cuando se habla de Investigación-Acción en el aula educativa, ésta presenta una tendencia a reconceptualizar el campo de la investigación educacional en términos más participativos y con miras a esclarecer el origen de los problemas, los métodos didácticos, los conocimientos significativos y la comunidad de docentes, y se ha impulsado sobre todo desde las mismas Universidades y desde los Centros de Investigación educacional, oficiales y privados," (Martínez, 2000, p. 30)

La investigación, a partir del trabajo de campo, buscó comprender las diferentes particularidades de los estudiantes y su contexto vivencial, para su desarrollo se tuvieron en cuenta las siguientes fases: a). Diagnóstico: comprendió la recolección de información que involucraba el contexto escolar y comunitario de cada estudiante; b). Formulación: se relacionó con el desarrollo de las estrategias y metodología referente al logro de cada uno de los objetivos planteados; c). Implementación: referida a la aplicación de estrategias evaluativas que connoten los alcances de la investigación-acción realizada; d). Construcción de sentido: abarca el análisis crítico y reflexivo acerca del proceso investigativo y actividades de retroalimentación a la Investigación Acción con su respectivo documento final.

A continuación, se presenta el análisis de la secuencia didáctica teniendo en cuenta las diferentes etapas y los procesos desarrollados en cada una de ellas.

\section{ETAPA DE COMPRENSIÓN.}

En esta etapa se desarrollaron diferentes eventos en los cuales se involucró el contexto de los estudiantes, se presentó la situación problema y se hizo un esquema de solución.

\section{PRESENTACIÓN DEL CONTEXTO.}

Mediante diálogo entre docente y estudiantes, se habló acerca de los resultados de la prueba diagnóstica y se hizo énfasis en las diferentes actividades que a diario desarrollan sus familias. Una de las actividades más relevantes de la prueba diagnóstica es el trabajo con la ganadería y sus derivados como es la leche; en este momento, dimos importancia a esta clase de eventos y los utilizamos para hacer diálogos que nos llevasen al estudio del objeto fracción. Estos nos sirvieron como de punto de partida para la resolución de la situación problema planteada en la secuencia didáctica.

\section{PRESENTACIÓN DE LA SITUACIÓN PROBLEMA.}

En esta etapa del proceso se presentó a los estudiantes el documento con la secuencia didáctica; se hizo la lectura guiada para que, de esta manera, los estudiantes pudieran hacer intervenciones, preguntar aspectos de su 
interés o hablar de situaciones de su diario vivir. También, los estudiantes podían trazar tareas o caminos a seguir para resolver las diferentes preguntas presentes en la secuencia didáctica.

\section{CONSTRUCCIÓN DEL ESQUEMA.}

Durante la construcción del esquema cada estudiante podía hacer nuevas preguntas o interrogantes qué, según ellos, al resolverlas podían conducirlos a encontrar las respuestas a las preguntas generales de la secuencia didáctica.

También, se realizó un listado de los elementos y materiales necesarios qué, según los estudiantes, se necesitaban para llegar a las respuestas que se planteaban en la secuencia didáctica.

\section{ETAPA DE DESCONTEXTUALIZACIÓN.}

En esta etapa, los estudiantes, por medio de la investigación, exploraron y consolidaron conceptos y procedimientos necesarios para resolver la situación problema. Este proceso lo desarrollaron con ayuda de sus familiares, es decir, por medio del trabajo en casa y con material manipulativo aportado por el docente, sus familiares $o$ acudientes.

Al igual, los estudiantes, teniendo en cuenta la secuencia didáctica, desarrollaron procesos generales referentes a la actividad matemática (registros semióticos de representación) enriqueciendo su esquema con conceptos y procedimientos.

\section{ETAPA DE RESOLUCIÓN DE LA SITUACIÓN PROBLEMA.}

En la etapa de resolución cada estudiante de forma individual, en presencia del docente, creó su propia estrategia de resolución relacionando sus saberes previos, el diario vivir en su comunidad o entorno y los procesos adquiridos anteriormente (registros semióticos de representación).

Así, finalmente cada estudiante dio solución a la situación problema con el acompañamiento del docente como guía o facilitador del aprendizaje.

\section{ETAPA DE VALORACIÓN.}

En la etapa de valoración, además de la revisión, aclaración y corrección de la secuencia didáctica, se presentó a los estudiantes una situación problema muy parecida a la dada en la prueba de diagnóstico para la cual fue necesario aplicar los conceptos y procedimientos trabajados con anterioridad (fracción y sus registros semióticos de representación). De esta manera, se logró verificar los alcances del trabajo con la secuencia didáctica y los cambios en los procesos matemáticos relacionados con el objeto fracción.

\section{RESULTADOS}

Se puede afirmar que el desarrollo de la secuencia didáctica basada en la resolución de problemas contextualizados trae grandes beneficios en cuanto al aprendizaje del objeto fracción, más aún cuando para solucionarlos hacemos uso y trabajamos diferentes registros semióticos de representación; cuando un estudiante encuentra sentido al estudio del objeto que aprende, le es mucho más fácil incorporar en sus registros mentales, y los procesos y procedimientos matemáticos, mejor aún si se trabaja pasando por diferentes registros semióticos de representación. Después de analizar la prueba diagnóstica encontramos que los estudiantes poseen muchos obstáculos relacionados con la apropiación del objeto matemático fracción, lo más relevante, fue la dificultad que ellos presentaban a la hora de realizar las conversiones del objeto matemático (fracción) en los diferentes registros semióticos de representación. Por ende, se hizo importante diseñar e implementar estrategias conducentes a minimizar los obstáculos matemáticos 
presentados por los estudiantes. La estrategia que se utilizó, fue la implementación de una secuencia didáctica basada en la resolución de problemas contextualizados al sector rural donde habitaban los estudiantes y sus familias, ésta involucró el objeto matemático fracción en diferentes registros semióticos de representación.

A continuación, presentamos algunas evidencias de resultados basados en la prueba final presentada por los estudiantes de grados cuarto y quinto del año lectivo 2020 de la Institución Educativa las Mercedes sede Golondrinas municipio de Chiscas Boyacá.
En la Figura 6 se puede evidenciar que la Estudiante 2 (E2), a partir del análisis de la Situación 1.1, dada en el registro semiótico lenguaje común, pudo claramente pasar al registro semiótico esquema pictográfico y aritmético. Además, presentó claridad al entender los enunciados que requerían la comprensión en lenguaje matemático, e idear figuras o pictogramas adecuados para poder dar una respuesta acorde a la situación planteada. Del mismo modo, la mayoría de los estudiantes del grupo de investigación, logró comprender el enunciado, y hacer las conversiones adecuadamente.



Fig.6 Transformación de conversión del registro en lenguaje común al registro esquema pictográfico y lenguaje aritmético Estudiante 2 (E2). Fuente: propia

Igualmente, en las Figuras 7 y 8 , se evidencia que el Estudiante 1 (E1), a partir de la lectura del Enunciado 1.2, y del análisis del dibujo, pudo realizar la transformación de conversión desde el registro semiótico lenguaje figural, al registro semiótico aritmético. También se pudo observar que el estudiante, realizó con facilidad y apropiación la simplificación de fracciones. Se puede admitir que es un contexto conocido por el estudiante, pero a pesar de ello, el proceso de transformación tiene cierto grado de dificultad, al igual comparado con la prueba diagnóstica los avances son muy significativos por parte de todos los estudiantes en esta prueba. 

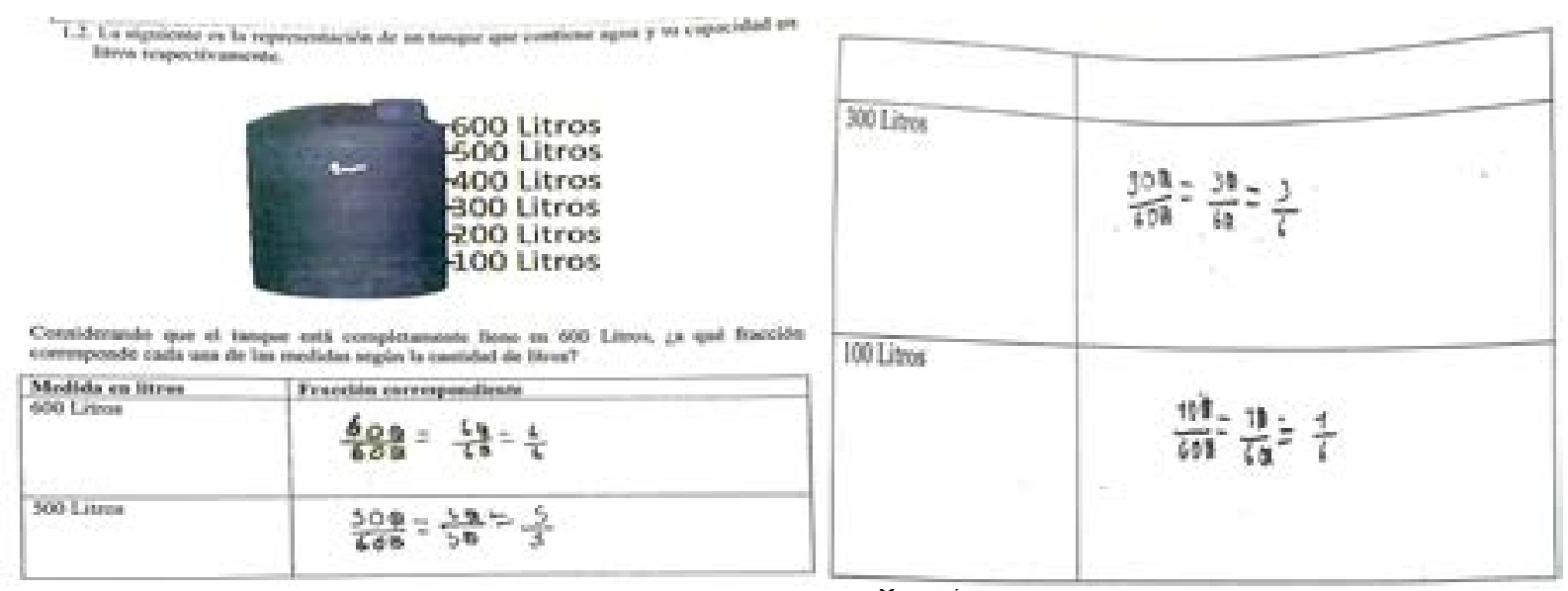

el registro semiótico lenguaje figural al registro aritmético, E1. Fuente: propia.

En el Enunciado 1.3 de la prueba final (Figura 9), los estudiantes, a partir de la comprensión del enunciado y del análisis de la imagen debían hacer la transformación de conversión desde el registro semiótico lenguaje figural, al registro semiótico lenguaje común. En este caso, el trabajo desarrollado por el Estudiante
3 (E3), estuvo acorde a los requerimientos de la prueba. El paso de la representación gráfica al lenguaje común y a la representación aritmética en el sistema decimal evidenció que los estudiantes comprendían el objeto matemático en diferentes representaciones y lo expresaban correctamente.



Fig. 9 Transformación de conversión desde los esquemas pictográficos al registro en lenguaje común E3. Fuente: propia.

En la Figura 10 se muestra que, el estudiante E4 teniendo en cuenta el Enunciado 1.4 debía hacer una transformación de tratamiento desde el registro aritmético con escritura decimal a escritura fraccionaria, además, tenía que realizar un esquema donde necesitó utilizar el registro figural y se evidenció un alto grado de asertividad en sus análisis Duval (2004). Se aclara que la prueba fue idéntica para todos los estudiantes y ellos, lograron hacer las transformaciones de una manera inequívoca. Esto nos permite reafirmar que los planteamientos de situaciones contextualizadas ayudaron y son de vital importancia en la construcción de aprendizajes significativos, específicamente, al aprendizaje del objeto matemático fracción, haciendo uso de 
los registros semióticos de representación.

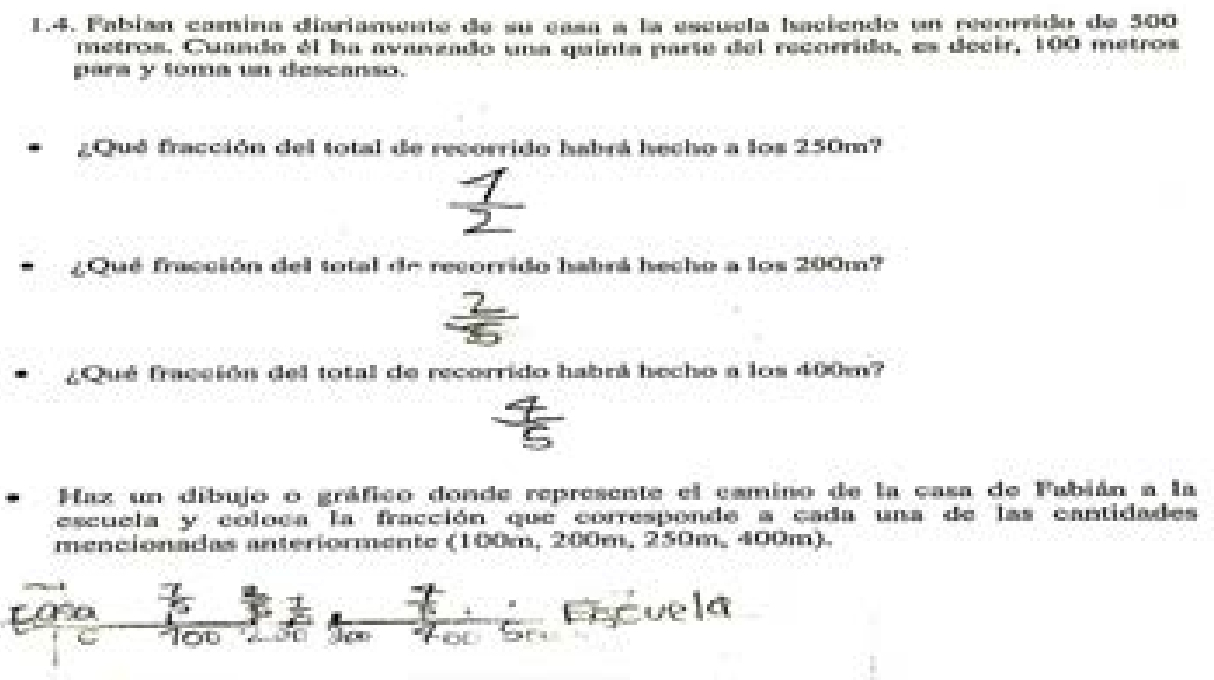

Fig. 10 Transformación de tratamiento desde el registro aritmético con escritura decimal a escritura fraccionaria E4.

El punto 2 del cuestionario, pretendía que los estudiantes planteasen una situación problema que requiriese el uso de las fracciones para solucionarla; la Figura 11 permite ver que, la totalidad de los estudiantes logró comprenderla y realizarla. En este caso, el estudiante 1 (E1) planteó una situación en el registro semiótico en lenguaje común, para solucionarla utilizó los registros pictográfico y aritmético, desarrolló una transformación de conversión adecuada Duval (2004).

2. Wian a y resuelvo una situncion problema de tu entorno, donste para solucionarla soa n, sario utilizar las meciones,

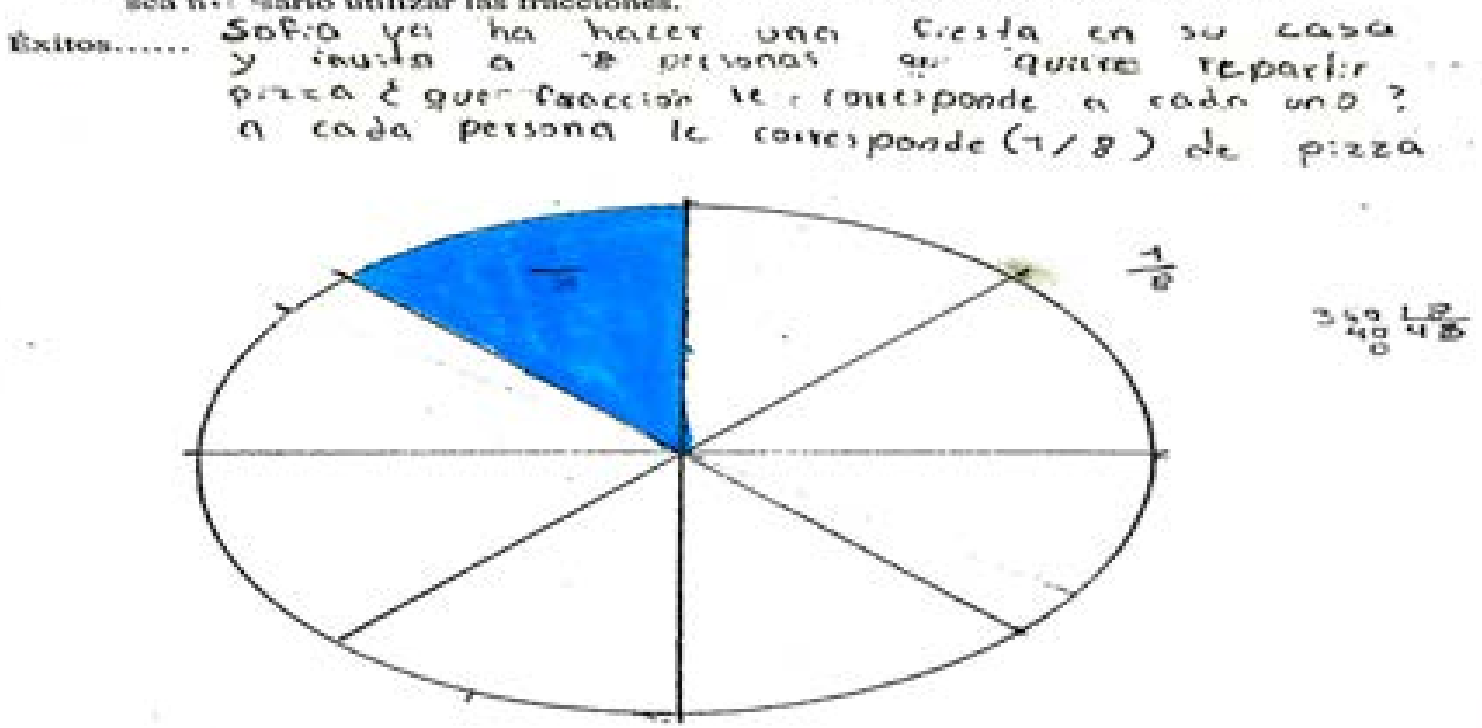

Fig. 11 Resolución de problemas desde el registro en lenguaje común con transformación de lenguaje común al registro pictográfico y aritmético E1. 


\section{DISCUSIÓN}

Haciendo un comparativo entre la prueba diagnóstica, aplicada al inicio del proceso, con la prueba final, encontramos hallazgos interesantes que nos permiten validar la importancia de trabajar los diferentes registros semióticos de representación en situaciones contextualizadas. Para los estudiantes es más significativo el estudio de objetos matemáticos desde la resolución de problemas, y ente caso, orientados por la teoría de representaciones semióticas, puesto que, al realizar las diferentes transformaciones, tanto de tratamiento como de conversión, pueden construir mejores aprendizajes, también, le hallan placer y gusto a el objeto matemático que aprenden.

A continuación, se presentan tablas de resumen en donde se aprecia el cambio en los procesos mentales de los estudiantes.

Tabla 1. Situación 1.1.

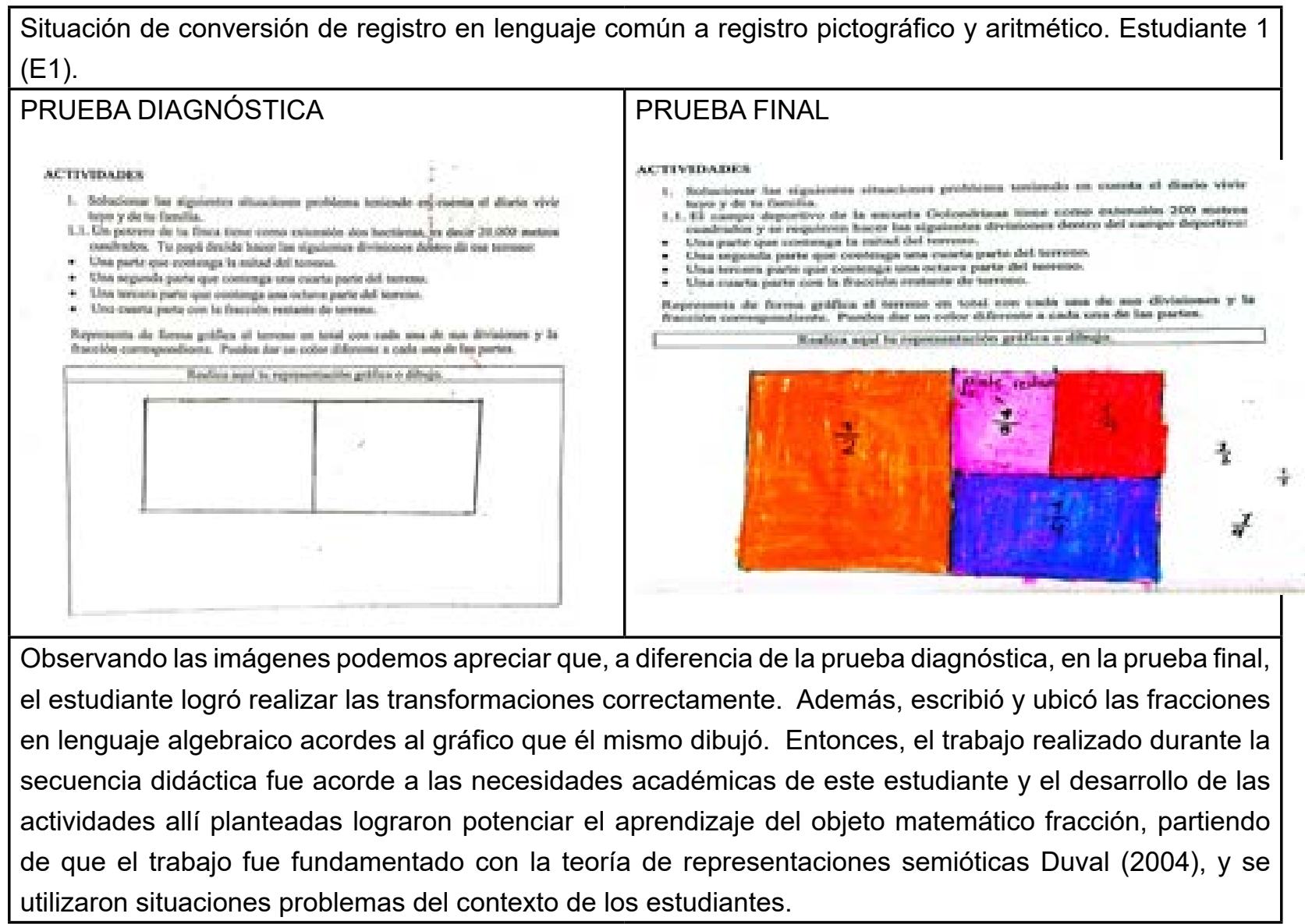


Tabla 2. Situación 1.2.




Tabla 3. Situación 1.3.

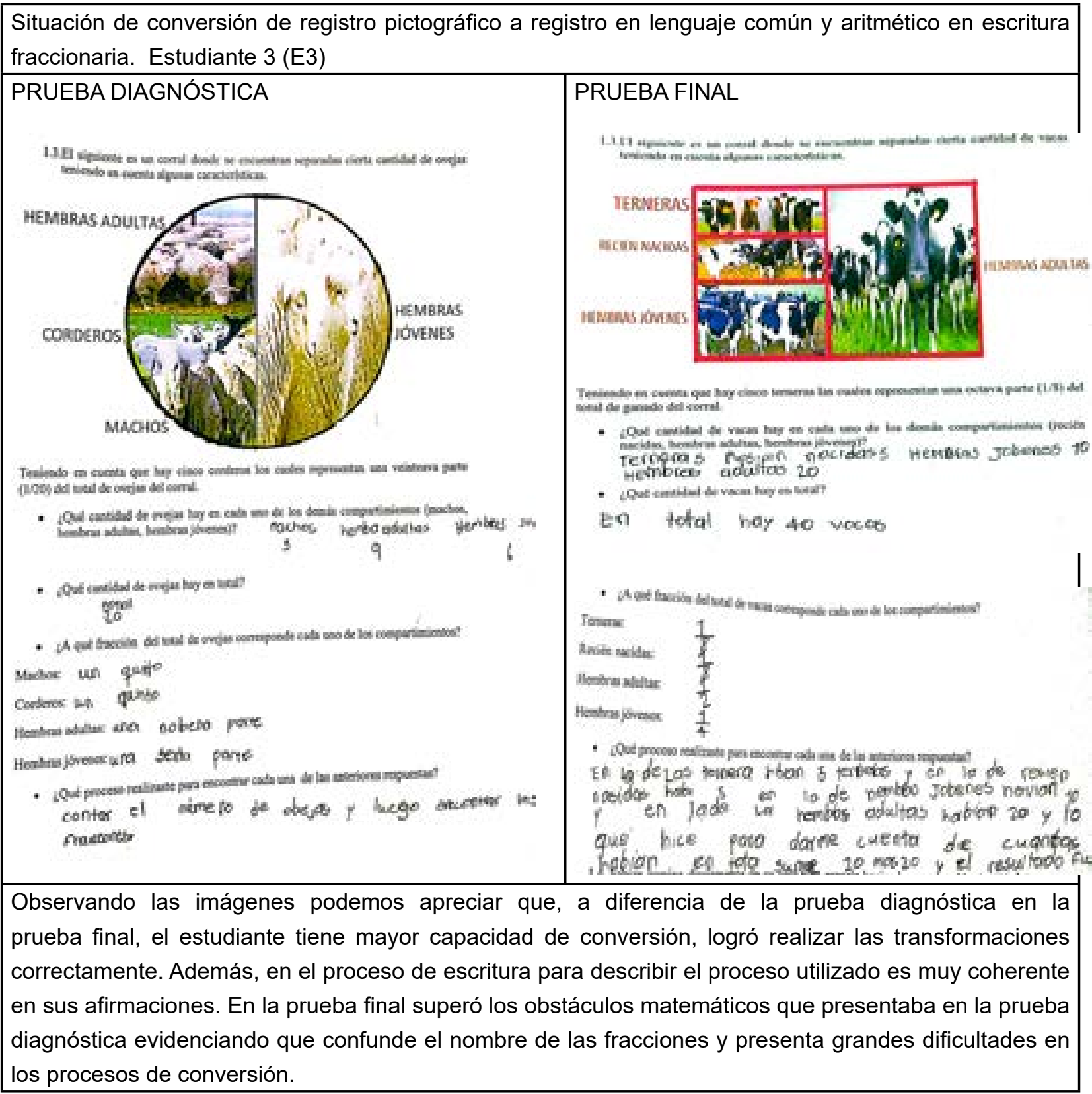


Tabla 4. Situación 1.4

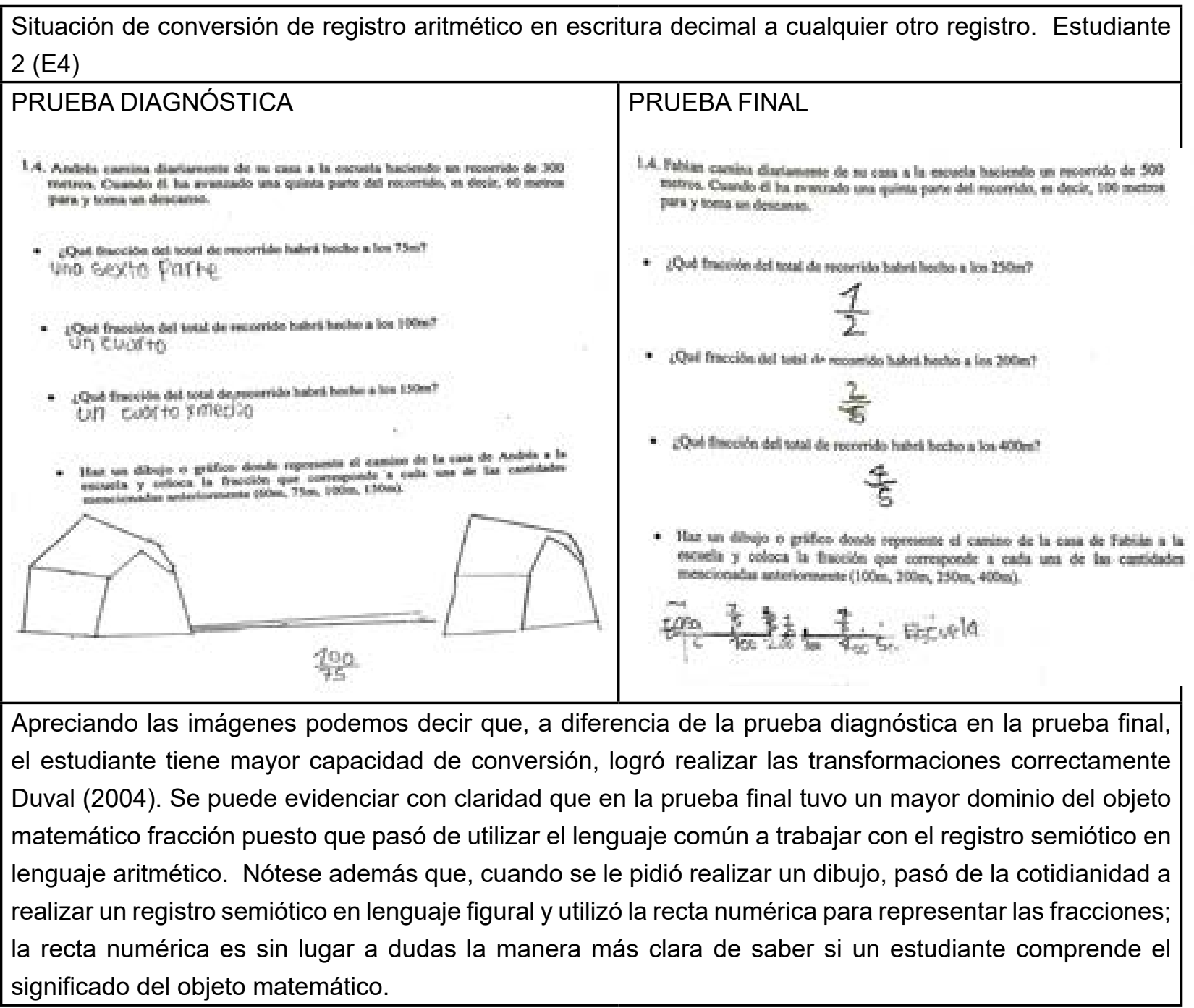

\section{CONCLUSIÓN}

El contexto socio-cultural de los estudiantes en los acontecimientos de aula de clase de matemática resultó ser un recurso pedagógico esencial en la comprensión formal de objetos matemáticos básicos como lo es la fracción. Así mismo, en correspondencia con el trabajo realizado por Rodriguez (2019), se logró evidenciar que la teoría de representaciones semióticas de Duval (2017) es de vital importancia para los procesos de enseñanza aprendizaje en el campo de la matemática; más aún si se contextualiza en un enfoque de resolución de problemas que incorporan el entorno, en nuestro caso las vivencias propias de la ruralidad en las que está inmersa la comunidad educativa objeto de estudio. El entorno en este caso, fue una fuente rica, en cuanto a la cantidad de situaciones vivenciales que en él se encuentran y que se pueden llevar al aula para su estudio. En particular, se aprovechó el hecho que los estudiantes, en compañía de sus padres u otros familiares, deben nombrar el objeto matemático fracción en lenguaje común para poder hacer sus menesteres cotidianos, por ejemplo, a diario ellos utilizan expresiones como: un litro de leche, medio litro de leche, media pastilla de cuajo, un cuarto de camino, tres quintas partes de un terreno, un cuarto de panela, media naranja, la mitad de ese lápiz, 
etc. Las transformaciones, tanto de conversión como de tratamiento en los registros semióticos de representación potencian el aprendizaje de objetos matemáticos (fracción). En nuestro caso, a pesar de que la investigación se desarrolló en una zona rural dispersa, muy alejados de los avances tecnológicos, con aulas multigrado, en época de pandemia mundial y trabajando desde casa; se evidenció un avance significativo en la construcción del objeto matemático (fracción) y fue notorio el interés, la participación, el deseo de aprender o solucionar problemas $\mathrm{y}$, mucho optimismo por parte de los estudiantes debido a que se trabajó con situaciones muy particulares de su contexto y haciendo uso de los diferentes registros semióticos de representación. Se trabajó con cuatro estudiantes, y como hecho significativo se resalta que todos evidenciaron notorios avances en su proceso de aprendizaje. Teniendo en cuenta la prueba final, se puede hacer un análisis individual de los estudiantes: el estudiante $E 4$, no fue claro cuando en el numeral 1.3 se le pidió describir el proceso que realizó para encontrar las respuestas, y generalizó las ideas sin llegar a detalles que serían muy importantes para la investigación. En el caso del estudiante E3 logró realizar una explicación más detallada en cada una de sus respuestas e hizo un uso adecuado de las transformaciones semióticas tanto de tratamiento como de conversión. El estudiante E2 no realizó el proceso de irreductibilidad de fracciones en el numeral 1.2 evidenciando que se debió hacer un trabajo más profundo con esta estudiante o, que al momento de la prueba no se le pidió realizar dicho proceso. En la prueba final, la estudiante E1 demostró poder realizar o solucionar cada una de las situaciones sin presentar dificultades notorias y las representaciones realizadas fueron acordes a cada una de las situaciones. En general, los estudiantes presentan más dificultades para realizar tratamientos de conversión desde el registro semiótico de las figuras geométricas al registro semiótico de lenguaje aritmético en escritura fraccionaria.
Todo lo anteriormente mencionado nos permite concluir que el uso adecuado de estrategias de aula que incorporen el contexto de los estudiantes en situaciones problema extraídas de su cotidianidad favoreció el aprendizaje de un objeto vital en desarrollo del pensamiento matemático: el objeto fracción. Así mismo, implementar la teoría de representaciones semióticas de Duval (2004), coadyuvó a que los estudiantes pudieran poner en práctica procesos de tratamiento y conversión entre las diferentes representaciones que dicho objeto matemático posee.

\section{REFERENCIAS BIBLIOGRÁFICAS}

Arias, F. G. (2012). El Proyecto de Investigación. Caracas: Episteme.

Butto Zarzar, C. (2013). EL APRENDIZAJE DE FRACCIONES EN EDUCACIÓN PRIMARIA: UNA PROPUESTA DE ENSEÑANZA EN DOS AMBIENTES. IBERO AMERICANA, 38.

Cid, E., Godino, J. D., \& Batanero, C. (2002). Sistemas Numéricos y su Didáctica para Maestros. Matemática y su Didáctica para Maestros, 167-196.

D`Amore , B. (1998). Elementi di didactica della matematica. Sao Paulo: 2007.

D`Amore , B. (2007). Elementos de la Didáctica de la Matemática . Sao Paulo: Livraria da Física.

D`Amore, B., Fandiño, M. I., \& Iori, M. (2013). La Semiótica en la didáctica de la Matemática. Bogotá: Magisterio.

D'Amore , B. (2001a). Concettualizzazione, registri di rapresentazioni semiotiche e noetica. Bologna: Pitagora.

Deely, J. (2003). The Semiotic Animal. Congresso tomista internazionale (págs. 2-5). Roma: Pontificia Accademia di San Tommaso.

Deely, J. (2003). The word "semiotics": Formation and origins. Roma: Pontificia Accademia di San Tommaso. 
Duval, R. (1996). Quel cognitif retenir en didactique des mathématiques? Recherche en Didactique des Mathématiques. , 16, 3, 349-382.

Duval, R. (2004). Semiosis y Pensamiento Humano Registros Semióticos y Aprendizajes Intelectuales. Cali: Segunda edición, Universidad del Valle Instituto de Educación y Pedagogía Grupo de Educación Matemática.

Duval, R. (2006). Un análisis cognitivo de problemas de comprensión en el aprendizaje de las matemáticas. Estudios educativos en matemáticas, 103-131.

Duval, R. (2006a). Trasformazioni di rappresentazioni semiotiche e prassi di pensiero in matematica. La matematica e la sua didattica., 4, 585-619.

Duval, R. (2008). Eight problems for a semiotic approach in mathematics education. Sense Publisheers., 39-61.

Duval, R. (2017). Understanding the Mathematical Way of Thinking - The Registers of Semiotic Representations. Switzerland: Springer International Publishing AG.

Duval, R., \& Sáenz-Ludlow, A. (2016). Comprensión y Aprendizaje en Matemáticas: Perspectivas Semióticas Seleccionadas. Bogotá: Universidad Distrital Francisco José de Caldas.

Elliott, J. (13 de Abril de 2000). La investigaciónacción en educación. Londres: Morata. Obtenido de Google scholar: https:// scholar.google.es/scholar?lookup $=0 \& q=$ La+investigaci\%C3\%B3n+acci\%C3\%B $3 n+e n+l a+e d u c a c i \% C 3 \% B 3 n .+4 \% C 2 \%$ AA\&hl=es\&as_sdt $=0,5 \&$ scioq $=$ elliot +20 00+investigacion+acci\% $\mathrm{C} 3 \% \mathrm{~B} 3 \mathrm{n}$

Fandiño, M. I. (2010). Múltiples aspectos del Aprendizaje de las Matemáticas. Bogotá: Magisterio.

Gaviria Uribe, G. A. (7 de 03 de 2016). Estrategia didáctica para trabajar el concepto de fracción como relación Parte-Todo en grado quinto, teniendo en cuenta su origen histórico. Bogotá: Universidad Nacional de Colombia. Obtenido de Opendoar: file:///C:/Users/LENOVO/ Downloads/germanalfonsogaviriauribe.2016.pdf

Godino, J. D. (2002). Un enfoque ontólogico y semiótico de la cognición matemática. Recherches en Didactique des Mathématiquies, Vol. 22, 237-284, .

Gómez Alfonso, B., Sanz García, M. T., \& Huerta Gabarda, I. (2016). Problemas Descriptivos de Fracciones. Bolema, Rio Claro: ISSN 1980-4415.

Hernández Sampieri, R., Fernández Collado, C., \& Baptista Lucio, M. d. (2014). Metodología de la Investigación. México D.F:: McGrawHillEducatión.

Martínez Miguélez, M. (2000). La investigaciónacción en el aula. Agencia Académica, 27- 39.

Martínez, C., \& Lascano, M. (2001). Acerca de Dificultades para la Enseñanza y el Aprendizaje de las Fracciones. EMA, 4-6.

MEN;. (2007). Lineamientos Curriculares Para el Área de Matemáticas. Bogotá: Ministerio de Educación Nacional.

Plata, J. (14 de Abril de 2020). Linea de Tiempo de las Fracciones. Obtenido de Linea de Tiempo de las Fracciones.: https://www. sutori.com/story/linea-de-tiempo-de-losnumeros-fraccionarios--ZaiifvdJKbAMVfhQemA6qrWL

Polya, G. (1989). Cómo plantear y resolver problemas. México: Trillas.

Radford, L. (2004). La generalizzazione matematica come processo semiotico. Bollettino dei docenti di matematica, 3953.

Rodriguez Pérez, Y. B. (2019). Fracciones y Realidad. Tunja: Universidad Pedagógica y Tecnológica de Colombia.

Sanders Peirce , C. (1976). The New Elements of Mathematics . Carolyn Eisel: The Hague: Mouton Publishers. 